Tijana S. Vesić Pavlović* Univerzitet u Beogradu

Mašinski fakultet https://doi.org/10.18485/analiff.2018.30.1.12 $811.163 .41 ' 367.62: 811.111^{\prime} 367.62$

Originalni naučni rad Primljen: 28.03.2018. Prihvaćen: 02.07.2018.

\title{
STRUKTURIRANJE SPORTA POMOĆU METAFORA PUTOVANJA U ENGLESKOM I SRPSKOM JEZIKU
}

\begin{abstract}
Predmet rada je strukturiranje domena SPORTA pomoću metafora čiji izvorni domen je kretanje po putanji. Teorijsko-metodološke postavke kognitivne lingvistike, u kojoj se tvrdi da je proširenje značenja leksema motivisano različitim pojmovnim mehanizmima i zasnovano na preslikavanjima koja se uspostavljaju između izvornog i ciljnog domena, čine osnovu analize. Istraživanje je sprovedeno na skupu engleskih i srpskih leksema koje označavaju komponente kretanja po putanji (ablativnost, perlativnost, adlativnost i prostor po kome se kretanje odvija) i posmatrano je proširenje njihovog značenja u domen SPORTA. Primeri za engleski i srpski jezik ekscerpirani su iz reprezentativnih korpusa dva jezika. Pokazuje se da se u konceptualizaciji SPORTA koriste različiti aspekti topologije sheme PUTANJE, sa različitim pokretnim metaforičkim entitetima i odredištima. U oba jezika, dominantne su metafore DUGOROČNE SVRSIHODNE AKTIVNOSTI SU PUTOVANJA i SVRHA RADNJE JE ODREDIŠTE KRETANJA, kojima se naglašava neophodnost ulaganja truda kako bi se postigao uspeh u sportu. Takođe, postoji i slučaj u kome se sport strukturira kao pokretni entitet, pri čemu se osvetljava drugi aspekat sportskih uspeha ili neuspeha kao događaja koji se pojavljuju na putanji, čime se umanjuje uloga sportiste ili tima u njihovom ostvarenju.
\end{abstract} jezik.

Ključne reči: pojmovne metafore, sport, putovanje, engleski jezik, srpski

\section{Uvod}

Predmet istraživanja u ovom radu jeste strukturiranje domena SPORTA pomoću pojmovnih metafora zasnovanih na izvornom domenu kretanja po putanji, koje se, u širem smislu, mogu označiti kao metafore PUTOVANJA. Domen SPORTA uključuje različite pojmove, poput takmičara (sportiste,

tvesic@mas.bg.ac.rs 
sportskog kluba, reprezentacije) i takmičenja (pojedinačne utakmice, lige, turnira, prvenstva), kao i različite vrsta ciljeva kojima se teži (npr. pobeda, medalja, trofej, prvo mesto). Cilj ovog rada jeste utvrđivanje toga koji aspekti sporta se strukturiraju pomoću iskustva s kretanjem na putanji i koje pojmovne metafore leže u osnovi ovakve konceptualizacije, kao i poređenje engleskog i srpskog jezika u ovom pogledu.

Analiza sprovedena u radu se zasniva na teorijskim i metodološkim postavkama kognitivne lingvistike (Klikovac, 2008, Kövecses, 2002, Lakoff, 1993, Lakoff \& Johnson, 2003[1980], Lakoff \& Johnson, 1999, i dr.). U kognitivnoj lingvistici podrazumeva se da je proširenje značenja reči motivisano i zasnovano na pojmovnim mehanizmima koji leže u njegovoj osnovi i omogućavaju da se apstraktni, iskustvu manje dostupni pojmovi razumeju putem konkretnih pojmova (Lakoff \& Johnson, 2003[1980]). Stoga se, da bi se ispitala konceptualizacija domena SPORTA pomoću iskustva s kretanjem po putanji, u radu razmatra proširenje značenja leksema koje u osnovnom značenju označavaju jednu od komponenti kretanja po putanji (ablativnost, perlativnost ili adlativnost) i prostor po kome se kretanje odvija i koji putnik prelazi u domen SPORTA. U kategoriji ablativnosti obuhvaćene su sledeće lekseme: engleski predlog from i srpski od, kao i engleski glagoli go away i depart i srpski krenuti i otići. Engleski predlog through i glagoli pass i go, kao i srpski predlog kroz i glagoli proći i ići uključeni su kao predstavnici perlativnosti. U kategoriji adlativnosti, razmatrali smo proširena značenja engleskih glagola come i arrive i predloga to i towards, kao i srpskih glagola doći i stići i predloga do, prema and $k a$. U kategoriji prostora po kome se kretanje odvija i koji putnik prelazi posmatrali smo proširenje značenja engleskih imenica path i road i srpskih staza i put. Korišćena je građa iz reprezentativnih elektronskih jezičkih korpusa engleskog (British National Corpus) i srpskog jezika (Korpus savremenog srpskog jezika Matematičkog fakulteta Univerziteta u Beogradu 2013), prikupljena u okviru obimnijeg istraživanja metaforičkih preslikavanja sheme PUTANJE u engleskom i srpskom jeziku (Vesić Pavlović, 2015). Iz korpusa je najpre izdvojeno oko $10 \%$ primera za upotrebu navedenih leksema, a zatim su odabrani oni primeri u kojima je došlo do proširenja značenja u domen SPORTA. Tako je dobijeno ukupno 36 primera za engleski i 125 primera za srpski jezik, na kojima je urađena kvalitativna analiza prikazana u radu. Iako je broj primera za engleski jezik dobijen na ovaj način znatno manji od broja primera koji su pronađeni za srpski jezik, ovako 
formiran korpus primera ipak može poslužiti za utvrđivanje nekih opštih pravilnosti u konceptualizaciji SPORTA u engleskom i srpskom jeziku, što će tokom analize biti pokazano.

Konceptualizacija domena SPORTA već je bila tema proučavanja različitih kognitivnolingvističkih studija. Ranija istraživanja pokazuju da je jedna od najčešće korišćenih pojmovnih metafora u konceptualizaciji sporta metafora SPORT JE RAT, o čemu svedoče primeri iz engleskog jezika poput the two battling teams, my team did not use the right strategy (Kövecses, 2002: 75). ${ }^{1} \mathrm{U}$ osnovi ove metafore jeste kulturna predstava o sportu kao ratnoj igri, a mnogi prototipični sportovi poput fudbala, ragbija, rvanja ili boksa upravo su se razvili iz nekog oblika borbe (Kövecses, 2002). Prethodne studije potvrđuju i da je figurativni jezik veoma važan u širem okviru diskursa $u$ kome se sport konceptualizuje. Strukturiranje utakmica ili sportskih nadmetanja kao rata uobičajeno je u novinskom diskursu (Bishop \& Jaworski, 2003). Silaški (2009) pokazuje da se u naslovima u srpskoj sportskoj štampi često javljaju inovativne, metonimijski zasnovane metafore za konceptualizaciju pobede i poraza. Jezik kojim se govori o sportu može imati i ulogu uspostavljanja snažne kolektivne identifikacije sa nacionalnim fudbalskim timom kao simbolom zajednice u celini (Čudomirović, 2014: 156).

U delu rada koji sledi daćemo kratak pregled teorijskih postavki kognitivnolingvističkog pristupa na kome je analiza zasnovana. U trećem delu predočićemo rezultate analize proširenja značenja odabranih leksema engleskog i srpskog jezika i pojmovne metafore koje leže u osnovi konceptualizacije sporta pomoću iskustva s kretanjem po putanji. U završnom delu osvrnućemo se na dobijene rezultate i dati preporuke za buduća istraživanja.

\section{Teorijski okvir istraživanja}

Pojmovna metafora predstavlja ,viđenje ili razumevanje jedne pojave kao druge (ili jednog iskustvenog domena kao drugog)“ (Klikovac,

$1 \quad$ Oblast sporta u literaturi se navodi i kao izvorni domen (Kövecses, 2002). Produktivnost sporta kao izvornog domena zasnovana je na činjenici da sport generalno podrazumeva niz određenih pravila, kao u primeru He tried to checkmate her (Kövecses, 2002: 18). Sportske metafore, naročito one zasnovane na pojmovima vezanim za fudbal, veoma su česte u političkom diskursu u srpskom jeziku (Silaški, Đurović et al., 2009), a takođe prožimaju i diskurs o kapitalizmu (Cudd, 2007). 
2008: 66), što znači da se struktura izvornog domena iz koga potiču metaforički izrazi preslikava na strukturu ciljnog domena, koji je apstraktniji i manje blizak iskustvu (na primer, žIVOT JE PUTOVANJE). Proučavanje metafora u okviru kognitivne lingvistike podrazumeva posmatranje metaforičkih izraza kao površinskih, jezičkih realizacija dubljih pojmovnih preslikavanja koje im leže u osnovi: „naš pojmovni sistem, u skladu s kojim mislimo i delamo, u svojoj prirodi bazično je metaforičan" (Lakoff \& Johnson, 2003[1980]: 3). To zapravo znači da, na primer, o životu ne samo da govorimo kao o putovanju, već ga tako i doživljavamo.

Kretanje u prostoru po određenoj putanji spada u osnovna čovekova iskustva. Usled postojanja stalnih paralela u iskustvu između kretanja u prostoru i drugih domena, ono predstavlja važan okvir u odnosu na koji se vrše razne druge konceptualizacije (Zlatev, 2007). Iz svakodnevnog iskustva znamo da putanje povezuju jednu prostornu tačku s drugom (Johnson, 1987). U kognitivnoj lingvistici, putanja se posmatra kao slikovna shema koja predstavlja obrazac čulne interakcije i motoričke aktivnosti koji se iznova ponavlja i daje strukturu ljudskom iskustvu (Johnson 1987: XIV). Kretanje po putanji podrazumeva postojanje početne tačke, završnu tačku i niz tačaka koje ih povezuju, a pored osnovnih elemenata, javljaju se i različite „uloge“ u shemi PUTANJE: putnik koji se kreće, trasa od početne do završne tačke, put koju putnik zapravo prelazi, pozicija i smer putnika u određenom trenutku, prava krajnja tačka do koje putnik dolazi, a koja ne mora da bude i željeno odredište (Lakoff \& Johnson, 1999: 33). Svi oni igraju važnu ulogu u preslikavanju sheme PUTANJE na elemente ciljnog domena.

Odnosi između elemenata izvornog domena kretanja i najopštijih ciljnih domena na koje se domen kretanja preslikava u literaturi se obično podvode pod veliki metaforički sistem STRUKTURE DOGAĐAJA (Lakoff, 1993), sačinjen od različitih podmetafora, kao što su STANJE JE MESTO, PROMENA JE KRETANJE, UZROK JE SILA, RADNJA JE SAMOIZAZVANO KRETANJE, SVRHA RADNJE JE ODREDIŠTE KRETANJA, NAČIN NA KOJI SE RADNJA VRŠI ILI SREDSTVO ZA NJU JESTE PUTANJA KA ODREDIŠTU, TEŠKOĆE U RADNJI SU PREPREKE NA PUTU, PREDVIĐENI NAPREDAK JE RASPORED PUTOVANJA, SPOLJAŠNJI DOGAĐAJI SU KRUPNI POKRETNI PREDMETI $\mathrm{i}$ DUGOROČNE SVRSISHODNE AKTIVNOSTI SU PUTOVANJA. U okviru ovih metafora javljaju se i nove podmetafore, pa tako preslikavanje SVRHA RADNJE JE ODREDIŠTE KRETANJA obuhvata i preslikavanja NAPREDOVANJE JE KRETANJE NAPRED, UČINJENI NAPREDAK JE PREĐENA RAZDALJINA, NAZADOVANJE 
JE KRETANJE UNAZAD, NEDOSTATAK SVRHE JE NEDOSTATAK SMERA, NEPOSTOJANJE NAPRETKA JE ODSUSTVO KRETANJA itd. (Lakoff, 1993). Najobuhvatniji pojmovni domeni koji se strukturiraju pomoću metaforičkog sistema STRUKTURE DogaĐAja su VReme, Život, AKTIVnost, stanje itd. (Klikovac, 2004, 2006; Vesić Pavlović, 2015, 2016).

Kada se govori o metaforičkim preslikavanjima vezanim za shemu PUTANJE, često se napominje da su ona zasnovana na scenariju PUTOVANJA. Pojam scenarija uveo je Lakoff (1987: 285-286), navodeći da scenario obuhvata početno stanje, niz događaja i konačno stanje, tako da početno stanje odgovara početnoj tački putovanja, konačno stanje odredištu, a niz događaja koji se dešavaju u međuvremenu odgovara međutačkama na putanji. Muzolf je dalje razradio ovaj koncept, definišući ga kao niz pretpostavki koje članovi govorne zajednice imaju o tipičnim aspektima neke situacije iz izvornog domena (Musolff, 2006: 28). Shodno tome, putovanje se može smatrati metaforičkim scenarijom koji u sebi povezuje poddomene kretanja i putanje i realizuje se pomoću njihovih elemenata, s obzirom da je direktno povezan sa utelovljenim iskustvom kretanja po putanji (Silaški \& Đurović, 2014). U okviru scenarija putovanja, naročito je naglašeno očekivanje o dostizanju željenog cilja, vrednog različitih izazova koje putnik mora da prevaziđe (Zbierska-Sawala, 2004 u Silaški \& Đurović, 2014). Ovakav scenario putovanja utkan je u produktivnu pojmovnu metaforu DUGOROČNE SVRSISHODNE AKTIVNOSTI SU PUTOVANJA, potvrđenu u literaturi na primerima strukturiranja ljubavi kao putovanja (Lakoff, 1993) ili života kao putovanja (Lakoff \& Johnson, 1999).

Metafore zasnovane na scenariju PUTOVANJA imaju veoma važnu ulogu i u političkom diskursu, budući da se svrha političkog delovanja često konceptualizuje kao odredište putovanja, pri čemu se naglašava da je napor uložen u vršenje aktivnosti koje dovode do društvenog boljitka vredan truda (Charteris Black, 2004: 93-95). Iskustvo putovanja pogodno je i za objašnjavanje različitih faza napredovanja u karijeri (Smith-Ruig, 2008), kao i u oblasti religije, na primer, u Starom Zavetu, gde se duhovna aktivnost strukturira kao putovanje ka odredištu (Charteris-Black, 2004). Sport je kompleksna aktivnost koja podrazumeva niz pravila i uključuje različite faze u ostvarivanju zacrtanih ciljeva. Zato se čini naročito pogodnom za konceptualizaciju pomoću metafore DUGOROČNE SVRSISHODNE AKTIVNOSTI SU PUTOVANJA, što rezultati našeg istraživanja predstavljeni u odeljku koji sledi i potvrđuju. 


\section{Rezultati istraživanja}

U skupu analiziranih primera u kojima lekseme koje primarno označavaju komponente kretanja po putanji proširuju značenje u domen SPORTA primetili smo različite slučajeve u zavisnosti od toga šta se zapravo strukturira kao putovanje, a, u okviru toga, ko ili šta je pokretni entitet. Kao putovanje se konceptualizuje samo bavljenje sportom, postizanje nekog sportskog uspeha, kvalifikacije za sportsko takmičenje, samo sportsko takmičenje i utakmica ili meč. S druge strane, putnici mogu da budu sportisti, ekipe ili reprezentacije, kao i sam sport. Metafora konceptualizacije sporta kao putovanja odnosi se, dakle, na različite aspekte bavljenja sportom i uključuje različite pokretne entitete koji se kreću ka različitim metaforičkim orijentirima. Imajući ovo u vidu, u nastavku ćemo navesti šest slučajeva konceptualizacije elemenata domena SPORTA pomoću iskustva s kretanjem po putanji, razvrstavajući ih najpre prema pojmu koji se konceptualizuje kao putovanje i, dodatno, u odnosu na to ko ili šta je metaforički putnik. U pojedinim slučajevima, primeri koji potvrđuju njihovo postojanje pronađeni su samo u srpskom jeziku.

\subsection{Bavljenje sportom je putovanje, sportista je putnik}

U oba posmatrana jezika, bavljenje sportom može da se konceptualizuje kao putovanje na kome mladi sportista kreće iz određene tačke (početak karijere), prolazi kroz niz međutačaka na putu kao faza u razvoju karijere i dolazi do završne tačke putovanja koja je i željeni cilj, na primer, prvo mesto na rang listi ili svetski vrh. U ovom kontekstu, dominantna je metafora SVRHA SPORTSKE AKTIVNOSTI JE ODREDIŠTE KRETANJA, koju ilustruju dolenavedeni primeri za engleski i srpski jezik. U primeru 1 za engleski jezik, dodatno se profilišu i teškoće u postizanju cilja sportske aktivnosti kao prepreke na putu sportiste koji se metaforički kreće.

\section{Engleski:}

(1) Rocky road to top: Damon Hill, who has progressed from being a hard-up member of a punk rock band to one of Formula One's most envied drivers, admitted last night that he had never had it so good. 
Srpski:

(2) Janko je po Tipsarevićima Brusjanin, a po majci Vlasotinčanin. Odavde, iz Bele reke, gde je letos bio na pripremama, krenuo je ka osvajanju juniorskog svetskog trona.

(3) Dvadesetogodišnji Đoković sigurno korača putem ka svetskom broju jedan.

(4) Uprkos neberićetnom periodu, opstaje u samom vrhu, (...), ali je suštinsko pitanje kada će i da li će Jankovićeva da načini taj ključni korak ka prvom mestu na svetu.

\subsection{Sportski uspeh je putovanje, tim je putnik}

U ovom slučaju, sportski tim, klub ili reprezentacija predstavljaju putnike čije se bavljenje sportom konceptualizuje kao putovanje ka željenom odredištu, koje može da bude postizanje najboljeg rezultata (na primer, svetski vrh, titula) ili dobra forma, koja je važna za ostvarivanje dobrih sportskih rezultata. $U$ analiziranim primerima iz korpusa, ovaj slučaj javio se samo u srpskom jeziku. Kao i u prethodnom slučaju, dominantno je pojmovno preslikavanje SVRHA SPORTSKE AKTIVNOSTI JE ODREDIŠTE KRETANJA.

(5) Od 1995. kada su naši odbojkaši krenuli ka svetskom vrhu osvajanjem bronzane medalje na Evropskom prvenstvu.

(6) Setite se, kada je Zvezda pre desetak godina nezadrživo išla ka evropskoj $i$ svetskoj tituli, tribine njenog ogromnog stadiona bile su krcate.

(7) Idemo ka sve boljoj igri i formi, što moramo da iskoristimo protiv Danske.

(8) Do željene forme došli su u najvažnijem trenutku. Navijači Crvene zvezde bili su veoma zadovoljni.

U skladu sa metaforom NAČIN NA KOJI SE RADNJA VRŠI ILI SREDSTVO ZA NJU JESTE PUTANJA KA ODREDIŠTU, perspektiva kluba predstavlja kretanje određenim putem, a orijentir i željeni cilj u ovom slučaju je uspeh uopšte.

(9) Onome koji bi pre nekoliko godina upozoravao da Zvezda ne ide dobrim putem vrlo brzo bi u samoj redakciji bio ,isključen mikrofon“ (...). 


\subsection{Kvalifikacije za sportsko takmičenje su putovanje, sportista/tim je putnik}

Primere za konceptualizaciju procesa kvalifikacija za sportsko takmičenje kao putovanja pronašli smo i u engleskom i u srpskom jeziku. Metaforički pokretni entiteti mogu da budu sportisti, timovi ili reprezentacije. Utakmice u kojima je potrebno učestvovati i pobediti kako bi se okončao proces kvalifikacija konceptualizuju se kao prolazne tačke na putanji koje je neophodno preći kako bi se stiglo do odredišta, tj. obezbeđivanja učešća na željenom takmičenju (turniru, šampionatu, Olimpijskim igrama) (u skladu sa metaforom PREDVIĐENI NAPREDAK U KVALIFIKACIJAMA JE RASPORED PUTOVANJA). Druge reprezentacije ili timovi posmatraju se kao prepreke na putu do željenog cilja (npr. prva prepreka kao odlasku na Evropsko prvenstvo je savladana, Partizan je na poslednjoj stepenici [...] dočekala „, velika rampa“), što je u skladu sa pojmovnim preslikavanjem TEŠKOĆE U POSTIZANJU CILJA SPORTSKE AKTIVNOSTI SU PREPREKE NA PUTU.

Engleski:

(10) It was a brilliant performance, enthused Toby Mullins, the ladies' coach who has led them to the championship in his first season in charge.

Srpski:

(11) Put do Svetskog šampionata 2002. godine u Japanu i Koreji biće i težak i dug, ali i za najduži put prvi korak je važan.

(12) Prva prepreka ka odlasku na Evropsko prvenstvo 2010. godine u Austriju je savladana.

(13) Partizan je na poslednjoj stepenici ka elitnom evropskom klupskom fudbalskom društvu dočekala ,velika rampa“.

\subsection{Sportsko takmičenje je putovanje, sportista/tim je putnik}

Različita takmičenja (utakmice, teniski turniri, svetski i evropski šampionati, Olimpijske igre) takođe se strukturiraju kao putovanje. Početna tačka putovanja je niži rang takmičenja, a putnici (sportisti, timovi, reprezentacije) prelaze niz međutačaka (razigravanje po grupama/kolima, osminu finala, četvrtfinale, polufinale) da bi stigli do konačnog cilja - fi- 
nala, medalje ili trofeja. U ovakvoj konceptualizaciji naglašava se neophodnost prolaženja svih faza do postizanja konačnog cilja, u skladu sa pojmovnom metaforom PREDVIĐENI NAPREDAK NA SPORTSKOM TAKMIČENJU JE RASPORED PUTOVANJA. Kao i u ranijim slučajevima, teškoće u ostvarivanju cilja sportske aktivnosti (na primer, učešća u završnom delu šampionata) konceptualizuju se kao prepreke na putu, kao u primeru 20 (trnovit put do završnice šampionata).

\section{Engleski:}

(14) The road to the finals gets rougher for competitors in the ABA national quarter-finals at Gateshead Leisure Centre tonight ( $8 \mathrm{pm})$, when the North-East Counties champions meet the North West title holders.

(15) The road to a fourth Miami title does not get any easier for Djokovic with a possible semi-final meeting with 17-times Grand Slam winner and two-times Miami champion Roger Federer up next.

(16) The Pumas path to the final saw them account for the second Hallamshire squad represented at the weekend, thus ending any aspirations of Yorkshire success.

\section{Srpski:}

(17) Od drugog do četvrtog kola igrao je prvi put sa velemajstorima i sve tri partije dobio.

(18) Moramo najpre prokrčiti put do polufinala i finala, a tek onda da razmišljamo o Mađarima i odlučujućem susretu sa njima o zlatu.

(19) Do te titule može se stići samo ako se osvoji najviše poena u pet disciplina.

(20) Put do završnice šampionata Starog kontinenta biće izuzetno trnovit, jer je sa Srbijom u društvu čak sedam selekcija.

Pri kretanju po putanji, kretanje napred povezuje se sa bržim dostizanjem cilja, tako da se grupna faza takmičenja doživljava kao međutačka na putanji, a četvrtfinale, polufinale ili finale kao one tačke koje su bliže konačnom cilju, u skladu s pojmovnom metaforom NAPREDOVANJE NA SPORTSKOM TAKMIČENJU JE KRETANJE NAPRED (primeri 22, 23). Takođe, određena udaljenost od konačnog cilja, trofeja ili titule podrazumeva i određenu verovatnoću njegovog osvajanja, u skladu s metaforom UČINJENI NAPREDAK JE PREĐENA RAZDALJINA (primeri 21, 24). 
Engleski:

(21) Defend Lewis says he hopes that public pressure will force Bowe to fight him but after the euphoria of his win over Ruddock and the anticipation of becoming champion, he finds himself as far from the title as ever.

Srpski:

(22) Po najbolja dva iz četiri grupe otići će dalje.

(23) Igraćemo na našem terenu i nadam se da ćemo posle revanša mi biti tim koji će ići dalje.

(24) Prvi put korak od trofeja: Novak Đoković

Sam šampionat može da se konceptualizuje i kao sadržatelj u okviru koga se odvija putovanje sportista ili tima (the way through the Championship, napredovati kroz Evroligu).

\section{Engleski:}

(25) You have to have all those ingredients and then you must drive at the top of your ability and sustain that level right the way through the Championship.

Srpski:

(26) Mislim da će biti spreman i da će još napredovati kroz Evroligu.

\subsection{Utakmica/meč je putovanje, sportista/tim je putnik}

$\mathrm{Na}$ osnovu primera pronađenih u korpusu, možemo da izdvojimo dva slučaja konceptualizacije meča kao putovanja. U prvom, meč se strukturira kao putovanje na kome putnik (sportista ili tim) mora da pređe sve tačke na putanji kako bi okončao meč. Kao i u prethodnom slučaju, meč ili njegovi delovi (set) posmatraju se kao sadržatelj kroz koji putnik prolazi (UTAKMICA/MEČ JE NIZ TAČAKA NA PUTANJI).

(27) Na Rolan Garosu sam prošla kroz mnogo teških mečeva.

(28) Imao sam dosta sreće što sam ovako lako prošao kroz četvrti set, jer je veoma lako sve moglo da se okrene na drugu stranu. 
U drugom slučaju, meč se dominantno doživljava kao putovanje ka pobedi (UTAKMICA/MEČ JE PUTOVANJE KA POBEDI). Međutim, ishod meča može biti i poraz, koji predstavlja neželjeno odredište putovanja do koga metaforički putnik stiže.

\section{Engleski:}

(29) With five regulars missing they rarely tested former colleague Woods in the Wednesday goal and it was Sheridan, another of Hillsborough's former Forest contingent, who set them on the way to victory.

(30) Warne's eight wickets at Old Trafford helped send England plunging towards defeat while lifting his overall haul to 39 .

Srpski:

(31) Dobru igru u prvom setu Tipsarević je uspeo da naplati, a već sredinom drugog seta imao je otvoren put ka pobedi.

(32) Prošlog četvrtka Makabi je došao do prvog trijumfa u gostima, bez teškoća protiv Unikahe u Malagi.

(33) U poslednjim sekundama meča Obilić je, zahvaljujući mladom Ivanu Pejčiću, stigao do važnih bodova i pobede.

(34) Redove naše ekipe poremetio je rani pogodak Sisea, ali je posle izjednačenja Mrdakovića usledio šokantan autogol Rajkovića, koji je sigurno trasirao put ka porazu.

Željeni cilj može da bude i izjednačenje, vođstvo ili prednost, koji se konceptualizuju kao međutačke na putu koji sportistu ili tim vodi do konačnog odredišta - pobede.

(35) Partizan je u drugih deset minuta, posle ulaska Petrovića, stigao do visokog vođstva.

(36) Francuska je lako stigla do ogromne prednosti u drugom setu 15:8.

(37) Tako su u prvom poluvremenu došli do izjednačenja 1:1.

(38) Uprkos tome, stvari su došle na svoje mesto i u 25. minutu Partizan je stigao $u$ vođstvo, a strelac je bio Saša Ilić iz jedanaesterca.

\subsection{Sport je putnik, rezultati sportske aktivnosti su putnici}

Iako se u prethodno navedenim slučajevima ciljevi ili rezultati sportske aktivnosti uglavnom strukturiraju kao orijentiri na putanji sportista ili tima, postoje i primeri u oba analizirana jezika u kojima su oni profilisani 
kao pokretni entiteti. U ovakvoj konceptualizaciji manje se naglašava uloga agensa (sportista, ekipe) u postizanju ovih ishoda.

Perspektiva sporta strukturira se kao izbor puta kojim se sam sport kreće (NAČIN NA KOJI SE AKTIVNOST VRŠI ILI SREDSTVO ZA NJU JESTE PUTANJA SPORTA KA ODREDIŠTU).

(39) Predstojeći dani i nedelje u kojima će se srpski bokseri naći pred velikim ispitima, na Beogradskom pobedniku i kvalifikacionom olimpijskom turniru u Atini, pokazaće kojim putem ide jedan od naših najtrofejnijih sportova.

Različiti pojmovi u domenu SPORTA, kao što su pobeda, poraz ili sportski rezultati, konceptualizuju se kao pokretni entiteti (REZULTATI SPORTSKE AKTIVNOSTI SU PUTNICI: the triumph came, došao je težak poraz). Sama pobeda ili poraz nastaju njihovim pojavljivanjem u određenoj tački na putanji, što je povezano sa opštijom metaforom konceptualizacije nastanka događaja kao njihovog pojavljivanja na putanji (Vesić Pavlović, 2015).

Engleski:

(40) The triumph came as a surprise to many fans (...).

(41) The tenth defeat of the season arrived and with it a place at the bottom of the table this time 2-1 at home to Peterborough.

Srpski:

(42) Neposredno zatim došao je težak poraz od Beopetrola, pa i u međunarodnom takmičenju od solunskog Iraklisa.

(43) Rezultati će sami doći, reči su selektora plavih.

(44) I tako su stigli ti sjajni rezultati, tako je napravljena serija koja se ne pamti u našoj odbojci.

\section{Diskusija i zaključna razmatranja}

$\mathrm{Na}$ osnovu analize proširenja značenja odabranih engleskih i srpskih leksema koje označavaju različite komponente sheme PUTANJE, možemo zaključiti da je topologija ove sheme veoma prisutna u konceptualizaciji elemenata domena SPORTA u oba analizirana jezika. Jedini slučaj koji nije potvrđen primerima u engleskom jeziku jeste konceptualizacija sportskog 
uspeha kao putovanja i sportskog tima kao putnika. No, primetno veći broj primera za konceptualizaciju SPORTA pomoću metafora PUTOVANJA u srpskom jeziku u analiziranom korpusu primera može dodatno ukazati i na veliku važnost koja se ovoj temi pridaje u javnom diskursu u Srbiji. Ustanovljena metaforička preslikavanja realizuju se proširenjem značenja gotovo svih obuhvaćenih leksema u oba jezika.

Strukturiranje sportskih takmičenja, bavljenja sportom ili pojedinačnih sportskih događaja zasnovano je na scenariju PUTOVANJA u kome putnici mogu biti sportisti ili timovi, a postoji i slučaj u kome sam sport ili sportski rezultati predstavljaju pokretne entitete, pri čemu se strukturira perspektiva pojedinačnog sporta ili ostvarivanje sportskih rezultata. Pojava da se isti pojam strukturira i kao orijentir i kao pokretni entitet pominje se u literaturi kao metaforička dualnost i često se javlja u slučajevima kada su pojmovna preslikavanja zasnovana na izvornom domenu KRETANJA (Lakoff\&Johnson, 1999).

U okviru dominantne metafore DUGOROČNE SVRSISHODNE AKTIVNOSTI SU PUTOVANJA, izdvojeno je više pojmovnih preslikavanja koja se odnose na različite aspekte konceptualizovanih pojava u okviru domena SPORTA, pOput SVRHA SPORTSKIH AKTIVNOSTI JE ODREDIŠTE KRETANJA, TEŠKOĆE U POSTIZANJU CILJA SPORTSKE AKTIVNOSTI SU PREPREKE NA PUTU, PREDVIĐENI NAPREDAK U KVALIFIKACIJAMA JE RASPORED PUTOVANJA, PREDVIĐENI NAPREDAK NA SPORTSKOM TAKMIČENJU JE RASPORED PUTOVANJA, NAČIN NA KOJI SE AKTIVNOST VRŠI ILI SREDSTVO ZA NJU JESTE PUTANJA SPORTA KA ODREDIŠTU, NAPREDOVANJE NA SPORTSKOM TAKMIČENJU JE KRETANJE NAPRED i UTAKMICA/MEČ JE PUTOVANJE KA POBEDI. Njima se naglašava ustrojenost sportskih događaja kao niza etapa koje vode do željene svrhe, od početka, preko središnjih faza, do kraja. Metafora DUGOROČNE SVRSISHODNE AKTIVNOSTI SU PUTOVANJA inače naglašava ove aspekte pri konceptualizaciji aktivnosti, u skladu sa sistemom metafore STRUKTURE DOGAĐAJA, a u kontekstu sporta dodatno potcrtava prirodu sportskih takmičenja i svih etapa koje ona uključuju. Strukturiranje bavljenja sportom kao putovanja na kome se mladi sportista kreće putanjom od najnižeg nivoa do željenog cilja takođe se može podvesti pod metaforičko preslikavanje KARIJERA JE PUTOVANJE (Inkson, 2002, Smith-Ruig, 2008, Vesić Pavlović, 2015).

$\mathrm{S}$ druge strane, u jednom broju primera za konceptualizaciju sporta javljaju se metaforička preslikavanja SPORT JE PUTNIK i REZULTATI SPORTSKE AKTIVNOSTI SU PUTNICI. Kao što se kod metafore DUGOROČNE SVRSISHODNE 
AKTIVNOSTI SU PUTOVANJA naglašava uloga putnika, tj. sportiste ili tima u postizanju cilja, tako se u slučaju kada je sam sport ili rezultat bavljenja sportom pokretni entitet u prvi plan stavlja relativna pasivnost učesnika. Ovaj nalaz u skladu je sa svojstvom pojmovnih metafora da neke aspekte pojma osvetljavaju, a druge prikrivaju (Lakoff\&Johnson 2003[1980]).

Stoga, možemo zaključiti da utvrđeno krilno metaforičko preslikavanje DUGOROČNE SVRSISHODNE AKTIVNOSTI SU PUTOVANJA, koje leži u osnovi konceptualizacije sporta kao putovanja usmerenog ka važnoj svrsi, naglašava napore neophodne da se ta svrha i ostvari, što je već potvrđeno i za neke druge aktivnosti u ranije pomenutim studijama. Linearnost sportskih događaja koji se odvijaju u određenom vremenskom okviru i u određenim fazama dodatno uslovljava njihovo strukturiranje pomoću iskustva s kretanjem po putanji. S obzirom da je u ovom istraživanju korišćen ograničen broj komponenti sheme PUTANJE i leksema koje ih primarno označavaju, kako bi se dobijeni zaključci potvrdili u budućim istraživanjima bi bilo neophodno obuhvatiti širi opseg leksema koje se odnose na specifične aspekte datih i drugih komponenti sheme PUTANJE i s njom povezanog scenarija PUTOVANJA, i posmatrati njihovo proširenje značenja u domen SPORTA. Takođe, na većem uzorku primera iz reprezentativnih korpusa dva analizirana jezika moguće bi bilo ispitati da li zaista postoji značajnija razlika u frekventnosti upotrebe pojmovnih metafora zasnovanih na scenariju PUTOVANJA u strukturiranju SPORTA u korist srpskog jezika.

\section{Literatura}

Bishop, H., \& Jaworski, A. (2003). 'We beat'em': nationalism and the hegemony of homogeneity in the British press reportage of Germany versus England during Euro 2000. Discourse and Society, 14(3), 243-271.

Charteris-Black, J. (2004). Corpus Approaches to Critical Metaphor Analysis. Basingstoke and New York: Palgrave Macmillan.

Cudd, A. E. (2007). Sporting metaphors: Competition and the ethos of capitalism. Journal of the Philosophy of Sport, 34(1), 52-67.

Čudomirović, J. (2014). Mobilizacija publike: izveštavanje dnevnih novina u Srbiji o nastupima fudbalske reprezentacije. Zbornik Matice srpske za filologiju i lingvistiku, LVII(2), 145-159. 
Inkson, K. (2002). Thinking creatively about careers: the use of metaphor. In M. Peiperl, M.A. Maury \& N. Anand (eds.), Career Creativity: Explorations in the Re-Making of Work (pp. 15-34). Oxford: Oxford University Press.

Johnson, M. (1987). The Body in the Mind: the Bodily Basis of Meaning, Imagination, and Reason. Chicago: The University of Chicago Press.

Klikovac, D. (2004). Metafore u mišljenju i jeziku. Beograd: Biblioteka XX vek.

Klikovac, D. (2006[2000]). Semantika predloga: Studija iz kognitivne lingvistike. Beograd: Filološki fakultet.

Klikovac, D. (2008). Šta je to metafora?. Književnost i jezik, 55(1-2), 57-76.

Kövecses, Z. (2002). Metaphor: A Practical Introduction. New York: Oxford University Press.

Lakoff, G. \& M. Johnson (1999). Philosophy in the Flesh. The Embodied Mind and Its Challenge to Western Thought. New York: Basic Books.

Lakoff, G. (1987). Women, Fire and Dangerous Things: What Categories Reveal About the Mind. Chicago: Chicago University Press.

Lakoff, G. (1993). The contemporary theory of metaphor. In A. Ortony (ed.), Metaphor and Thought. $2^{\text {nd }}$ edition (pp. 202-251). New York: Cambridge University Press.

Musolff, A. (2006). Metaphor scenarios in public discourse. Metaphor and Symbol, 21(1), 23-38.

Silaški, N. \& T. Đurović (2014). One Step Forward, Two Steps Back: Conceptualizing Serbia's EU Accession in Serbian and EU Discourse. In A. Musolff, F. MacArthur \& G. Pagani (eds.), Metaphor and Intercultural Communication (pp. 185-201). London/New York: Bloomsbury.

Silaški, N. (2009). Sportski diskurs u svetlu kognitivne lingvistike - konceptualizacija pobede i poraza u naslovima. Nasleđe, 14, 107-122.

Silaški, N., T. Đurović \& B. Radić-Bojanić (2009). Javni diskurs Srbije: Kognitivističko-kritička studija. Beograd: Centar za izdavačku delatnost Ekonomskog fakulteta u Beogradu.

Smith-Ruig, T. (2008). Making sense of careers through the lens of a path metaphor. Career Development International, 13(1), 20-32.

Vesić Pavlović, T. (2015). Metaforička preslikavanja slikovne sheme PUTANJE u engleskom i srpskom jeziku. Doktorska disertacija. Beograd: Filološki fakultet.

Vesić Pavlović, T. (2016). Konceptualizacija STANJA pomoću elemenata sheme PUTANJE u engleskom i srpskom jeziku. Zbornik Matice srpske za filologiju i lingvistiku, $\operatorname{LIX}(2), 151-163$. 
Izvori

British National Corpus (BNC). Dostupan na: http://corpus.byu.edu/bnc.

Korpus savremenog srpskog jezika Matematičkog fakulteta Univerziteta u Beogradu 2013. Dostupan na: http://korpus.matf.bg.ac.rs.

Tijana Vesić Pavlović

\section{Summary \\ THE STRUCTURING OF SPORT VIA JOURNEY METAPHORS IN ENGLISH AND SERBIAN}

The paper deals with the structuring of the domain of SPORT via the conceptual metaphors with the source domain of мотіоN. The analysis is based on the theoretical and methodological tenets of cognitive linguistics, which argues that polysemy rests on various underlying conceptual mechanisms, most notably, conceptual metaphors, and the mappings arising between the source and target domains. The research was performed on a set of English and Serbian lexemes which denote the components of moving along the path (departing, moving through intermediate points on the path, arriving, and the path along which motion takes place) and their meaning extension into the domain of SPORT was analysed. The examples used in the analysis were excerpted from the representative corpora of English and Serbian. It is shown that the conceptualisation of the SPORT domain relies on different aspects of the PATH schema topology, with different metaphorically moving entities and destinations. The dominant conceptual mappings are LONG-TERM PURPOSEFUL ACTIVITIES ARE JOURNEYS and PURPOSES ARE DESTINATIONS, which emphasise the necessity of investing vast efforts in achieving success in sports. Additionally, there is the case where sport itself or sports results are moving entities, which highlights another aspect of sport success or lack of success as something happening on its own, thus reducing the role of an athlete or a team in its achievement.

Key words: conceptual metaphors, sport, journey, English, Serbian. 